\title{
Resistant Starches (RS2 and RS3) have Variable Effects on Bone Mineral Status in Rats
}

\author{
Tasleem A. Zafar ${ }^{1}$, Berdine Martin ${ }^{2}$ and Connie M. Weaver*,2 \\ ${ }^{I}$ Department of Family Sciences, College for Women, Kuwait University, Kuwait; ${ }^{2}$ Department of Foods and Nutrition, \\ Purdue University, West Lafayette, IN 47907, USA
}

\begin{abstract}
Nondigestible oligosaccharides may increase mineral absorption by changing the intestinal environment. The effect of feeding a diet containing 5\% resistant starch, RS2 (uncooked native) or RS3, (cooked and retrograded) on calcium absorption and bone mineral status was studied in growing male rats for 4 weeks. Almost $100 \mathrm{~g}$ more feed was consumed with resistant starch compared to control in four weeks. Mineral status improved as determined by femur concentration, but not through absorption. Mineral content of femurs increased 12, 10 and 9\% for $\mathrm{Ca}, \mathrm{Mg}$ and $\mathrm{Zn}$ respectively, while Fe decreased $23 \%$ after feeding RS3, but not RS2, compared with the control group. There was no increase in the percent retention for any of the tested minerals. ${ }^{45} \mathrm{Ca}$ absorption capacity was not affected by either resistant starch. We conclude that resistant starches improve mineral status possibly through increased food consumption, but not through increased absorption efficiency.
\end{abstract}

Keywords: Resistant starch, calcium, magnesium, zinc, iron, bone, feed intake, rats.

\section{INTRODUCTION}

Carbohydrates, the major source of energy in the human diet, are primarily consumed as sugars, starch, and fiber. The ability to digest starch is intermediate between sugars and fiber. A portion of the starch plus its degradation products resist digestion in the stomach and reach the large bowel unabsorbed [1]. The amount of starch that resists digestion depends on the type of starch. According to Englyst et al. [2], based on in vitro digestibility, resistant starches are classified as follows: RS1, the physically inaccessible type packed in grains and seeds and low amylose cornstarch; RS2, the uncooked native starch granules such as those found in raw potato or green banana and uncooked high amylose cornstarch; and RS3, the cooked and subsequently cooled retrograded starch found in bread, cooked and cooled potato, cereals, and retrograded high amylose cornstarch. A fourth type, RS4, is chemically modified starch. After escaping absorption in the upper portion of the small intestine, resistant starches are extensively fermented by microflora in the large intestine to short chain fatty acids such as butyrate and propionate [3-5]. These organic acids lower the $\mathrm{pH}$ of the lumen which has the potential to increase solubility and thus absorption of minerals in the large intestine [5-8].

Mixed effects have been reported for resistant starches on mineral absorption. Younes et al. observed a significant increase in apparent calcium absorption by feeding 15\% [9] or $35 \%$ [10] raw potato starch (RS2) by weight with $0.75 \%$ dietary calcium to rats. Schulz et al. [11] reported increases in apparent absorption of both calcium and magnesium when rats were fed raw native RS2, but not the retrograded resistant starch (RS3). When two different sources of RS2, raw

*Address correspondence to this author at the Department of Foods and Nutrition, Purdue University, $700 \mathrm{~W}$. State Street, West Lafayette, IN 47907-1264, USA; Tel: (765) 494 8237; Fax: (765) 494 0674;

E-mail: weavercm@purdue.edu potato and high amylose starch, were compared at the same level and fed to rats for 7 days [12], no differences were found in calcium and magnesium absorption. Cecal concentrations of calcium, potassium, and phosphate, but not of magnesium, were significantly increased in rats fed either $25 \%$ or $50 \%$ amylose-rich starch, $10 \%$ lactulose or $10 \%$ pectin compared to the control [13]. The cecal pool of all these minerals was increased in a dose-dependent manner with the $25 \%$ and $50 \%$ amylose.

All of the studies cited above used high levels of resistant starch $(15$ to $50 \%)$ and some $[9,10]$ used higher levels of dietary calcium (up to $0.75 \%$ ). The calcium requirement for rats is $0.5 \%$. It is likely that any effect of calcium-absorption enhancers would be dampened above this level. The present study was designed to investigate the effect of two resistant starches, high amylose resistant cornstarch containing 60\% resistant starch (RS2) and a high amylomaize retrograded resistant cornstarch containing 55\% resistant starch (RS3), at $5 \%$ by weight on calcium absorption, mineral balance and bone mineral concentration in rats fed a $0.5 \%$ calcium diet.

\section{METHODS AND MATERIALS}

\subsection{Animals}

Ninety, five-week old (150-165 g), male SpragueDawley (Harlan, Indianapolis, IN, USA) rats were adapted to the AIN 93G diet for one week before assigning to their respective experimental diets. They were housed individually in stainless steel hanging cages with ad libitum access to deionized water and food. Day and night cycles were reversed. All procedures were approved by the animal care committee at Purdue University (West Lafayette, IN).

\subsection{Experimental Procedures}

After adaptation, rats were assigned to one of three treatment groups ( $n=30 /$ group); Group 1) control, Group 2) 
RS2 and Group 3) RS3. Rats in group 1 were given the nutritionally adequate AIN 93G diet (Table 1). Groups 2 and 3 were also given AIN 93G diet except for that $5 \%$ of the cornstarch was replaced with resistant starch (RS2, National Starch Chemicals Food Proc, Bridgewater, NJ, or RS3, prepared according to US Patent 6,013,299 and supplied by Kraft Foods, Glenview, IL) such that $5 \%$ of the diet was resistant starch. They were fed the diets ad libitum for four weeks (Table 1). Each dietary group was equally divided into 2 subgroups for oral vs. intraperitoneal (IP) administration of ${ }^{45} \mathrm{Ca}$. Four days before the termination of the study, all rats were fasted for 2 hours. The oral group was given the test meal $(25 \mathrm{mg}$ calcium as calcium acetate in double deionized water plus $10 \mu \mathrm{Ci}{ }^{45} \mathrm{Ca}$ in gavage solution) without starch to determine enhanced calcium absorption capacity of the rats after starch consumption. The IP group was given the calcium acetate by gavage and the $10 \mu \mathrm{Ci}{ }^{45} \mathrm{Ca}$ in $0.5 \mathrm{ml}$ saline was given as an intraperitoneal injection. Food was returned 2 hours after dosing.

\subsection{Sample Collection and Analyses}

Thirteen rats from each oral group were put in metabolic cages for four days to collect 24-hour urine and feces in 24-h pools at the end of the 4 week intervention. Food spillage and food consumption were carefully monitored for determination of apparent absorption and retention. After four days, body weights of all the rats were taken and they were sacrificed. Both femurs were extracted, weighed and their length measured. Left femurs, urine and feces were analyzed for ${ }^{45} \mathrm{Ca}$ radioactivity by $\beta$-Scintillation counting and for total calcium by ICP-OES, (Perkin Elmer, Optima 4300 DV, A Analyst 300, Perkin Elmer). Right femurs were measured for bone mineral density (BMD) and bone mineral content (BMC) using Dual X- ray Absorptiometry (DXA). Femurs were tested for breaking strength by a three point bending method on a TA-XT2 Texture analyzer (Texture Technolo- gies Corp., Scarsdale, NY). Femurs were brought to room temperature before breaking in the exact center using a test speed of $1 \mathrm{~mm} / \mathrm{s}$. Data were expressed as breaking strength (area under curve, $\mathrm{kg} \mathrm{X} \mathrm{m}$ ), stiffness (slope $\mathrm{kg} / \mathrm{m}$ ), and peak force ( $\mathrm{kg}$ at the peak).

${ }^{45} \mathrm{Ca}$ absorption was calculated as percent dose of ${ }^{45} \mathrm{Ca}$ in femurs of the oral group divided by percent ${ }^{45} \mathrm{Ca}$ in femurs of the IP group multiplied by 100 . Total calcium intake was estimated from the food consumed in four days while in the metabolic cages plus the test dose of $25 \mathrm{mg}$ calcium given in the gavage solution. Apparent minerals (calcium, magnesium, iron and zinc) absorption was calculated as intake fecal excretion for the last four days in the metabolic cages. Retention of the minerals was calculated as intake - (fecal + urinary excretion). Percent mineral retention was calculated as retention divided by mineral intake multiply by 100 . Diet samples were analyzed for mineral composition by ICP OES.

\subsection{Statistical Analysis}

Data are presented as means \pm SD. One way analysis of variance (ANOVA) and Tukey analyses as posthoc were used to determine significant differences at $\mathrm{p}<0.05$ (SAS, Carey, NC).

\section{RESULTS}

\subsection{Body Weight, Weight Gain, Femoral Weight}

Food intake was greater $(\mathrm{p}<0.05)$ in rats fed resistant starch compared to rats fed the control diet (Table 2). Initial and final body weights, weight gains, and femur weight and length were similar for all three groups.

\subsection{Metabolic Balance Study}

Rats fed resistant starches in their diets consumed significantly more food, and hence more $\mathrm{Ca}$ and other minerals,

Table 1. Composition of the Control and Modified AIN 93G Diets for Resistant Starches (RS2 and RS3) fed to Rats for 4 Weeks

\begin{tabular}{|l|l|l|l|}
\hline Ingredients (g/kg diet) & Control (AIN 93G) & RS2 & RS3 \\
\hline \hline Cornstarch & 397.5 & 314.5 & 306.5 \\
\hline Casein & 200 & 200 & 200 \\
\hline Dextrinized Starch & 132 & 132 & 132 \\
\hline Sucrose & 100 & 100 & 100 \\
\hline Soybean Oil & 70 & 70 & 70 \\
\hline Fiber & 50 & 50 & 50 \\
\hline Mineral Mix (93G) & 35 & 35 & 35 \\
\hline Vitamin Mix (93G) & 10 & 10 & 10 \\
\hline L-Cystine & 3 & 3 & 3 \\
\hline Choline Bitartrate & 2.5 & 2.5 & 2.5 \\
\hline RS2 ${ }^{*}$ & 0 & 83 & 0 \\
\hline RS3 & & 9 \\
\hline
\end{tabular}

Cornstarch was replaced by *RS2 (60\% resistant starch) and $* * \mathrm{RS} 3$ (55\% resistant starch) to provide $5 \%$ as resistant starch. 
Table 2. Effect of Feeding Control vs. $\mathrm{RS2}^{\$}$ or RS3 $^{\#}$ for Four Weeks on Total Food Intake Body Weight, and Right Femoral Weight and Length in Rats. Mean $\pm \mathrm{SD},(\mathrm{n}=30$ / group)

\begin{tabular}{|c|c|c|c|c|c|c|}
\hline Groups & Total Food Intake (g) & Initial Body Wt. (g) & Final Body Wt. (g) & Weight Gain (g) & Femoral Wt. (g) & Femoral Length (mm) \\
\hline \hline Control & $526 \pm 53^{\mathrm{a}}$ & $156 \pm 8$ & $317 \pm 17$ & $161 \pm 14$ & $0.96 \pm 0.05$ & $34.8 \pm 0.7$ \\
\hline RS2 & $618 \pm 43^{\mathrm{b}}$ & $156 \pm 7$ & $317 \pm 17$ & $160 \pm 16$ & $0.95 \pm 0.05$ & $34.9 \pm 0.6$ \\
\hline RS3 & $636 \pm 56^{\mathrm{b}}$ & $153 \pm 21$ & $315 \pm 22$ & $163 \pm 24$ & $0.94 \pm 0.06$ & $34.7 \pm 0.7$ \\
\hline
\end{tabular}

Group means with different superscripts were significantly different at $\mathrm{p}<0.05$.

${ }^{\$}$ RS2: Resistant starch 2.

\#RS3: Resistant starch 3.

compared to the control group (Table 3). Both apparent absorption and retention of $\mathrm{Ca}, \mathrm{Mg}$ and $\mathrm{Zn}$ but not $\mathrm{Fe}(\mathrm{p}<0.05)$ was increased in groups fed resistant starches. When corrected for increased food intake by calculating retention as percent intake, the difference among the groups disappeared (Table 3).

\subsection{Bone Mineral Analysis}

Calcium, $\mathrm{Mg}$ and $\mathrm{Zn}$ content of the femurs in the group fed RS3 was increased by $12 \%, 10 \%$ and $9 \%$ respectively compared to rats fed RS2 or the control diet $(\mathrm{p}<0.05)$. Rats fed RS3 had reduced Fe content in bones compared to the control group $(p<0.05)$ but no difference compared to the group fed RS2 (Table 4).

No significant difference was observed among the groups in bone mineral density (BMD) in any region of the femurs (proximal, central or distal); however, a trend towards an increase in bone mineral content (BMC) was found in the proximal region $(\mathrm{p}<\mathrm{T}=0.086)$ of rats fed $\mathrm{RS} 3$. Distal and central regions were not different among the groups (Table 5).

\subsection{Breaking Strength Measurements}

No difference was found among the groups fed control, RS2 or RS3 diets in the breaking strength of femurs in any of the parameters, i.e., maximum force, gradient or area (data not shown).

\section{5. ${ }^{45}$ Ca Analysis}

There was no significant difference in ${ }^{45} \mathrm{Ca}$ absorption capacity among rats fed control or resistant starch diets for 4 weeks. ${ }^{45} \mathrm{Ca}$ absorption capacity averaged $60.5 \pm 9 \%$ for the

Table 3. The Effect of Feeding ${ }^{\S}$ Control vs. Resistant Starches for the Last 4 Days of a 4 Week Intervention on Feed and Total Minerals Intake and Retention ${ }^{\S \S}$ in Rats

\begin{tabular}{|c|c|c|c|c|}
\hline Groups & Control & $\mathbf{R S 2}^{\$}$ & $\mathbf{R S 3}^{\#}$ & $P$ value \\
\hline Diet intake $(\mathrm{g} / 4 \mathrm{~d})$ & $77.8 \pm 9^{\mathrm{a}}$ & $87.5 \pm 10^{\mathrm{b}}$ & $88.0 \pm 9^{\mathrm{b}}$ & $<0.05$ \\
\hline $\operatorname{App}^{*}$ Ca absorp ${ }^{* *}(\mathrm{mg} / \mathrm{d})$ & $63 \pm 13^{\mathrm{a}}$ & $75 \pm 14^{\mathrm{b}}$ & $74 \pm 14^{\mathrm{b}}$ & 0.05 \\
\hline Ca retention $(\mathrm{mg} / \mathrm{d})$ & $62 \pm 6^{\mathrm{a}}$ & $73 \pm 14^{\mathrm{b}}$ & $73 \pm 13^{\mathrm{b}}$ & 0.06 \\
\hline Mg intake (mg/d) & $12 \pm 1.4^{\mathrm{a}}$ & $13 \pm 1.6^{\mathrm{ab}}$ & $14 \pm 1.4^{\mathrm{b}}$ & $<0.001$ \\
\hline App Mg absorp (mg/d) & $8 \pm 1.4^{\mathrm{b}}$ & $10 \pm 1.5^{\mathrm{a}}$ & $11 \pm 1.5^{\mathrm{a}}$ & $<0.001$ \\
\hline Mg retention (mg/d) & $7 \pm 1.2^{\mathrm{b}}$ & $8 \pm 1.9^{\mathrm{ab}}$ & $9 \pm 1.8^{\mathrm{a}}$ & $<0.05$ \\
\hline$\% \mathrm{Mg}$ retention & $62 \pm 06^{\mathrm{a}}$ & $64 \pm 10^{\mathrm{a}}$ & $64 \pm 8^{\mathrm{a}}$ & 0.73 \\
\hline Fe intake (mg/d) & $0.80 \pm 0.1^{\mathrm{a}}$ & $0.87 \pm 0.1^{\mathrm{ab}}$ & $0.95 \pm 0.09^{\mathrm{b}}$ & $<0.01$ \\
\hline Zn intake (mg/d) & $0.76 \pm 0.9^{\mathrm{b}}$ & $0.85 \pm 0.1^{\mathrm{a}}$ & $0.85 \pm 0.8^{\mathrm{a}}$ & $<0.05$ \\
\hline App Zn absorp (mg/d) & $0.24 \pm 0.11^{\mathrm{a}}$ & $0.31 \pm 0.15^{\mathrm{ab}}$ & $0.44 \pm 0.09^{b}$ & 0.02 \\
\hline Zn retention (mg/d) & $0.22 \pm 0.1^{\mathrm{a}}$ & $0.29 \pm 0.2^{\mathrm{b}}$ & $0.28 \pm 0.08^{\mathrm{b}}$ & 0.02 \\
\hline$\% \mathrm{Zn}$ retention & $29 \pm 12^{\mathrm{a}}$ & $34 \pm 14^{\mathrm{a}}$ & $33 \pm 08^{\mathrm{a}}$ & 0.57 \\
\hline
\end{tabular}

Mean $\pm \mathrm{SD}$, (n=13/group); Different letter superscripts within a row represent significant group mean differences at $\mathrm{p}<0.05$.

${ }^{8}$ Before putting in the metabolic cages, these rats were fed for 24 days on their respective diets.

${ }^{\$ \S}$ Mineral absorption, retention and \%retention are explained in the Section "Statistical Analysis".

${ }^{\$}$ RS2: Resistant starch 2.

${ }^{\#}$ RS3: Resistant starch 3.

${ }^{*}$ App: Apparent.

${ }^{* *}$ Absorp: Absorption. 
Table 4. Effect of Feeding Control vs. $\mathrm{RS2}^{\$}$ and $\mathrm{RS3}^{\#}$ for Four Weeks to Rats on Total Bone Ca, Mg, Zn and Fe Measured by ICP-EOS. Mean (mg/femur) \pm SD, $(\mathrm{n}=30 /$ group)

\begin{tabular}{|l|l|l|l|l|}
\hline Groups & Ca $(\mathbf{m g})$ & Mg (mg) & Zn $(\mathbf{m g})$ & Fe (mg) \\
\hline \hline 1. Control & $114 \pm 12^{\mathrm{a}}$ & $2.05 \pm 0.11^{\mathrm{a}}$ & $0.126 \pm 0.01^{\mathrm{a}}$ & $0.048 \pm 0.014^{\mathrm{a}}$ \\
\hline 2. RS2 & $115 \pm 14^{\mathrm{ab}}$ & $2.08 \pm 0.13^{\mathrm{a}}$ & $0.131 \pm 0.01^{\mathrm{ab}}$ & $0.040 \pm 0.011^{\mathrm{ab}}$ \\
\hline 3. RS3 & $128 \pm 13^{\mathrm{b}}$ & $2.26 \pm 0.19^{\mathrm{b}}$ & $0.137 \pm 0.01^{\mathrm{b}}$ & $0.037 \pm 0.006^{\mathrm{b}}$ \\
\hline
\end{tabular}

Different letter superscripts within a column represent significant difference at $\mathrm{p}<0.05$.

${ }^{\$}$ RS2: Resistant starch 2 .

\#RS3: Resistant starch 3 .

Table 5. Effect of Feeding Control vs. $\mathrm{RS2}^{\$}$ and $\mathrm{RS3}^{\#}$ for Four Weeks to Rats on Femoral BMD and BMC Measured by DEXA $(n=18$ /group). Mean \pm SD

\begin{tabular}{|c|c|c|c|c|}
\hline Groups & DXA Measurements & Proximal Femur & Central Femur & Distal Femur \\
\hline 1. Control & $\mathrm{BMC}(\mathrm{g})$ & $0.05 \pm 0.01$ & $0.12 \pm 0.01$ & $0.067 \pm 0.01$ \\
\hline \multirow[t]{2}{*}{ 2. RS2 } & $\operatorname{BMD}\left(\mathrm{g} / \mathrm{cm}^{2}\right)$ & $0.18 \pm 0.01$ & $0.18 \pm 0.01$ & $0.18 \pm 0.01$ \\
\hline & BMC (g) & $0.06 \pm 0.001$ & $0.12 \pm 0.01$ & $0.07 \pm 0.01$ \\
\hline
\end{tabular}

Different letter superscripts represent significant differences in group measures at ${ }^{\mathrm{T}} \mathrm{p}=0.086$.

${ }^{\$}$ RS2: Resistant starch 2 .

\#RS3: Resistant starch 3.

control group, $60 \pm 6 \%$ for rats in the RS2 group, and $59 \pm 6 \%$ for rats in the RS3 group.

\section{DISCUSSION}

This is the first report of the effect of resistant starches, RS2 and RS3, at 5\% of the diet on mineral absorption in rats fed the recommended levels of dietary calcium $(0.5 \%)$. Rats fed resistant starches consumed significantly $(\mathrm{P}<0.05)$ more food than rats on the control diet, yet the increased consumption did not result in increased weight gain (Table 2). These observations are consistent with other studies where diets containing resistant starch or dietary fiber have reduced energy absorption [14-16]. Significant reduction of postprandial glycemia and insulinemia accompanied with reduction in subjective sensation of satiety in humans have been shown $[15,17,18]$. However, no [19] or a small effect of resistant starch on appetite has also been reported [20].

In our study, apparent absorption of $\mathrm{Ca}, \mathrm{Mg}$, and $\mathrm{Zn}$, but not Fe was increased, by feeding RS2 and RS3 to rats. However, group differences disappeared when adjusted for intake differences as \% retention. Shultz et al. [21] and Hijene et al. [22] found that only RS2, but not RS3, increased $\mathrm{Ca}$ and $\mathrm{Mg}$ absorption in rats. Similarly, RS2 enhanced apparent $\mathrm{Ca}$, $\mathrm{Mg}, \mathrm{Cu}, \mathrm{Fe}$ and $\mathrm{Zn}$ absorption in rats fed either high amylose cornstarch or raw potato starch [23]. In contrast, in a human study [24] that fed green banana flour to ileostomy patients, $\mathrm{RS} 2$ did not change the apparent absorption of $\mathrm{Ca}, \mathrm{Mg}, \mathrm{Zn}$, $\mathrm{K}$ or $\mathrm{Na}$ while increased Fe excretion. RS2 enhanced $\mathrm{Ca}$ and Fe absorption in young piglets [25] but not in adult pigs [26]; additionally, a reduction in both $\mathrm{Ca}$ and $\mathrm{Mg}$ absorption was observed on RS2 but not on RS3 in older pigs. These inconsistent results clearly hamper our understanding of the mechanism underlying the role of resistant starch on mineral absorption.

Some research suggests that resistant starch is fermented in the colon by colonic microorganisms producing short chain fatty acids thus resulting in proliferation of mucosa and lowering of the $\mathrm{pH}$ in lumen, therefore, enhancement of mineral absorption [23,27,28]. RS2 was reported [21,29] to be more fermentable than RS3. In this case, we should have seen higher mineral absorption with RS2 compared to RS3. The lack of difference in mineral absorption on resistant starch (from raw banana flour) vs. control (cooked banana flour) in a human study [24] also counters that proposed mechanism. Yet Heijnen et al. [22] found that apparent, but not true absorption, of $\mathrm{Mg}$ was enhanced on RS2 compared to feeding RS3.

In the current study, no difference in percent retention between resistant starches and the control suggests no impact of possible mucosal proliferation or mucosal $\mathrm{pH}$ due to feeding of resistant startches. Furthermore, the lack of difference in the calcium absorption capacity from the diets, measured by $\%{ }^{45} \mathrm{Ca}$ absorption, suggests no enhanced mineral absorption capacity through an adapted intestinal epithelium with mucosal cell proliferation and increased surface area as others have reported $[10,30]$ at the levels we fed. This is also supported by our earlier study where a nondigestible oligosaccharide (inulin as Synergy 1) was fed for three months to ovariectimized rats [31]. Calcium absorption capacity was not enhanced by chronic feeding of this fructooligosaccharide as determined directly using kinetic modeling (WINSAAM) of oral and intraperitoneal tracers of calcium $\left({ }^{45} \mathrm{Ca}\right)$. 
A positive effect of $\mathrm{RS}$ on bone $\mathrm{Ca}, \mathrm{Mg}$ and $\mathrm{Zn}$ in the present study could be either due to its effect on mineral metabolism beyond absorption such as suppressing bone resorption or increased feed intake due to reduced caloric absorption. We previously found that Synergy 1 completely suppressed bone resorption, which was the largest effect that this nondigestible carbohydrate had on calcium metabolism in ovariectomized rats [31]. We did not measure bone resorption in the present study. While there was a trend toward increased BMC in proximal femur $(\mathrm{p}=0.06)$ in rats fed RS3 only; there was no significant difference between the groups in breaking strength of the femurs midshaft. This is likely due to the fact that dietary interventions tend to modify trabecular bone more than cortical bone [32] and the midshaft is primarily cortical bone. The role of resistant starch on $\mathrm{Fe}$ is not clear in the present study. Contrary to other studies in rats [23] and piglets [25], apparent Fe absorption in the present study was not affected by either RS2 or RS3 yet bone Fe was significantly reduced on RS3 feeding. Unlike a previous human study [24], we found no significant increase in Fe fecal excretion (data not shown). The possibility of an early enhancing effect of resistant starch on mineral absorption efficiency which adapts away over time with chronic feeding cannot be ruled out from our study as absorption was only measured after 4 weeks. Adaptation over time did not occur with Synergy [31], but has been shown with lactulose [33].

In summary, bone mineral content of $\mathrm{Ca}, \mathrm{Mg}$ and $\mathrm{Zn}$ was enhanced by RS3, but not by RS2. Bone Fe was decreased by RS3, but not by RS2. Many questions remain on the role of RS on mineral metabolism. Discrepancies in results from different labs could be related to differences in study design including: a) amounts and sources of RS, b) animal models, c) feeding duration, d) mode of feeding (ad libitum vs. controlled feeding), and e) length of fasting time before sacrifice. For example, fasting for longer times such as overnight could diminish some of the fiber effect on the mucosal cell lining.

Most of the studies to date have been in rats. Future research should be conducted in humans because of the marked differences in the digestive microflora between the two species and the rate and type of short chain fatty acid production, with the subsequent effect on luminal $\mathrm{pH}$. Raw starch is not a large part of the human diet. Mineralenhancing effects of starch may change with cooking as the starch transforms from native raw resistant starch to retrograded RS3.

\section{ACKNOWLEDGEMENT}

This project was funded by Kraft Foods, USA.

\section{REFERENCES}

[1] Cummings JH, Beatty ER, Kingman SM, Bingham SA, Englyst HN. Digestion and physiological properties of resistant starch in the human large bowel. Br J Nutr 1996; 75: 733-47.

[2] Englyst HN, Kingman SM, Cummings JH. Classification and measurement of nutritionally important starch fractions. Eur J Clin Nutr 1992; 46: S33-50.

[3] Phillips J, Muir JG, Birkett A, et al. Effect of resistant starch on fecal bulk and fermentation-dependent events in humans. Am J Clin Nutr 1995; 62: 121-30.

[4] Brouns F, Kettlitz B, Arrigoni E. Resistant starch and the butyrate revolution. Trends Food Sci Tech 2002; 13: 251-61.
[5] Topping DL, Clifton PM. Short-chain fatty acids and human colonic function: roles of resistant starch and nonstarch polysaccharides. Physiol Rev 2001; 81: 1031-64.

[6] Morohashi T, Sano T, Ohta A, Yamada S. True calcium absorption in the intestine is enhanced by fructooligosaccharide feeding in rats. J Nutr 1998; 128: 1815-8.

[7] Sesink AL, Termont DS, Kleibeuker JH, Van Der Meer, R. Red meat and colon cancer: dietary haem, but not fat, has cytotoxic and hyperproliferative effects on rat colonic epithelium. Carcinogenesis 2000; 21: 1909-15.

[8] Perrin P, Pierre F, Patry Y, et al. Only fibres promoting a stable butyrate producing colonic ecosystem decrease the rate of aberrant crypt foci in rats. Gut 2001; 48: 53-61.

[9] Younes H, Coudray C, Bellanger J, Demigne C, Rayssiguier Y, Remesy C. Effects of two fermentable carbohydrates (inulin and resistant starch) and their combination on calcium and magnesium balance in rats. Br J Nutr 2001; 86: 479-85.

[10] Younes H, Demigne C, Remesy C. Acidic fermentation in the caecum increases absorption of calcium and magnesium in the large intestine of the rat. Br J Nutr 1996; 75: 301-14.

[11] Schulz AG, Van Amelsvoort JM, Beynen AC. Dietary native resistant starch but not retrograded resistant starch raises magnesium and calcium absorption in rats. J Nutr 1993; 123: 1724-31.

[12] Lopez HW, Levrat-Verny MA, Coudray C, et al. Class 2 resistant starches lower plasma and liver lipids and improve mineral retention in rats. J Nutr 2001; 131: 1283-9.

[13] Demigne C, Levrat MA, Remesy C. Effects of feeding fermentable carbohydrates on the cecal concentrations of minerals and their fluxes between the cecum and blood plasma in the rat. J Nutr 1989; 119: 1625-30.

[14] Heijnen ML, Deurenberg P, van Amelsvoort JM, Beynen AC. Replacement of digestible by resistant starch lowers diet-induced thermogenesis in healthy men. Br J Nutr 1995; 73: 423-32.

[15] Tagliabue A, Raben A, Heijnen ML, Deurenberg P, Pasquali E, Astrup A. The effect of raw potato starch on energy expenditure and substrate oxidation. Am J Clin Nutr 1995; 61: 1070-5.

[16] Roberfroid MB. Caloric value of inulin and oligofructose. J Nutr 1999; 129: 1436S-7S.

[17] Raben A, Tagliabue A, Christensen, NJ, Madsen J, Holst JJ, Astrup A. Resistant starch: the effect on postprandial glycemia, hormonal response, and satiety. Am J Clin Nutr 1994; 60: 544-51.

[18] van Amelsvoort JM, Weststrate JA. Amylose-amylopectin ratio in a meal affects postprandial variables in male volunteers. Am J Clin Nutr 1992; 55: 712-8.

[19] Weststrate JA, van Amelsvoort JM. Effects of the amylose content of breakfast and lunch on postprandial variables in male volunteers. Am J Clin Nutr 1993; 58: 180-6.

[20] de Roos N, Heijnen ML, de Graaf C, Woestenenk G, Hobbel E. Resistant starch has little effect on appetite, food intake and insulin secretion of healthy young men. Eur J Clin Nutr 1995; 49: 532-41.

[21] Schulz AG, Van Amelsvoort JM, Beynen AC. Dietary native resistant starch but not retrograded resistant starch raises magnesium and calcium absorption in rats. J Nutr 1993; 123: 1724-31.

[22] Heijnen MLA, vandenBerg GJ, Beynen AC. Dietary raw versus retrograded resistant starch enhances apparent but not true magnesium absorption in rats. J Nutr 1996; 126: 2253-9.

[23] Lopez HW, Levrat-Verny MA, Coudray C, et al. Class 2 resistant starches lower plasma and liver lipids and improve mineral retention in rats. J Nutr 2001; 131: 1283-9.

[24] Langkilde AM, Champ M, Andersson H. Effects of high-resistantstarch banana flour (RS2) on in vitro fermentation and the smallbowel excretion of energy, nutrients, and sterols: an ileostomy study. Am J Clin Nutr 2002; 75: 104-11.

[25] Morais MB, Feste A, Miller RG, Lifschitz CH. Effect of resistant and digestible starch on intestinal absorption of calcium, iron, and zinc in infant pigs. Pediatr Res 1996; 39: 872-6.

[26] Heijnen ML, Beynen A. Effect of consumption of uncooked (RS2) and retrograded (RS3) resistant starch on apparent absorption of magnesium, calcium, and phosphorus in pigs. Z Ernahrungswiss 1998; 37: 3-17.

[27] Younes H, Coudray C, Bellanger J, Demigne C, Rayssiguier Y, Remesy C. Effects of two fermentable carbohydrates (inulin and resistant starch) and their combination on calcium and magnesium balance in rats. Br J Nutr 2001; 86: 479-85. 
[28] Younes H, Demigne C, Remesy C. Acidic fermentation in the caecum increases absorption of calcium and magnesium in the large intestine of the rat. Br J Nutr 1996; 75: 301-14.

[29] Olesen M, Rumessen JJ, Gudmand-Hoyer E. Intestinal transport and fermentation of resistant starch evaluated by the hydrogen breath test. Eur J Clin Nutr 1994; 48: 692-701.

[30] Remesy C, Levrat MA, Gamet L, Demigne C. Cecal fermentations in rats fed oligosaccharides (inulin) are modulated by dietary calcium level. Am J Physiol 1993; 264: G855-62.

[31] Zafar TA, Weaver CM, Zhao YD, Martin BR, Wastney ME. Nondigestible oligosaccharides increase calcium absorption and sup- press bone resorption in ovariectomized rats. J Nutr 2004; 134 : 399-402.

[32] Scholz-Ahrens KE, Schrezenmeir J. Inulin, oligofructose and mineral metabolism - experimental data and mechanism. Br J Nutr 2002; 87: S179-86.

[33] Brommage R, Binacua C, Antille S, Carrie AL. Intestinal calcium absorption in rats is stimulated by dietary lactulose and other resistant sugars. J Nutr 1993; 123: 2186-94.

Received: July 25, 2008

(c) Zafar et al.; Licensee Bentham Open.

This is an open access article licensed under the terms of the Creative Commons Attribution Non-Commercial License (http://creativecommons.org/licenses/by-nc/3.0/) which permits unrestricted, non-commercial use, distribution and reproduction in any medium, provided the work is properly cited. 